\title{
First evidence of Ixodiphagus hookeri (Hymenoptera: Encyrtidae) parasitization in Finnish castor bean ticks (Ixodes ricinus)
}

\author{
Jani Jukka Sormunen ${ }^{1,2}$ (D) Ella Sippola ${ }^{1,2} \cdot$ Kari Mikael Kaunisto $^{2} \cdot$ \\ Eero Juhani Vesterinen ${ }^{2,3}$ (D) Ilari Eerikki Sääksjärvi ${ }^{2}$
}

Received: 30 July 2019 / Accepted: 12 November 2019 / Published online: 19 November 2019

(C) The Author(s) 2019

\begin{abstract}
Ixodiphagus hookeri (Hymenoptera: Encyrtidae) is a parasitoid wasp specialized in parasitizing the larvae and nymphs of ticks (Acari: Ixodidae). As parasitized ticks die prior to reproduction, I. hookeri is seen as a prime biological control agent candidate. Despite this, little is known of their occurrence or ecology in northern Europe. The main aim of the current study was to determine whether adult wasps or parasitized ticks can be found from a tick-infested island in southwestern Finland, using field collections and molecular methods. Following the initial discovery of an adult I. hookeri female on Seili Island, we set out to collect further specimens via sweep netting and Malaise trappings between May and October 2017. Furthermore, 1310 Ixodes ricinus (1220 nymphs, 90 adults) collected from the island during 2012-2014 were screened for I. hookeri DNA using qPCR. Whereas no further wasp specimens could be collected via sweep netting or Malaise trappings, I. hookeri DNA was consistently detected in I. ricinus nymphs (annual minimum infection rates in 2012, 2013, and 2014: 2.3, 0.4, and 0.5\%, respectively), whereas all adult samples were negative. Although the annually repeated detections of parasitized ticks suggest that the wasp inhabits the island, further field and molecular surveys are needed to more comprehensively determine the status and stability of the population.
\end{abstract}

Keywords Parasitism $\cdot$ Parasitization $\cdot$ Parasitoids $\cdot$ qPCR $\cdot$ Biological control

Electronic supplementary material The online version of this article (https://doi.org/10.1007/s1049 3-019-00437-6) contains supplementary material, which is available to authorized users.

Jani Jukka Sormunen

jjtsor@utu.fi

1 Department of Biology, University of Turku, Turku, Finland

2 Biodiversity Unit, University of Turku, Turku, Finland

3 Department of Ecology, Swedish University of Agricultural Sciences, Uppsala, Sweden 


\section{Introduction}

Ticks (Acari: Ixodidae) and tick-borne diseases, particularly Lyme borreliosis and tickborne encephalitis (TBE), have become a growing problem in Europe and Russia in the twenty first century. In northern Eurasia, the two main vectors for the causative agents of these diseases are Ixodes ricinus (castor bean tick) and Ixodes persulcatus (taiga tick). In Fennoscandia - the region encompassing Finland, Norway, Sweden and regions of Russia in the Kola Peninsula and Karelia - the geographical distribution of I. ricinus has shifted northwards in recent decades (Jore et al. 2011; Jaenson et al. 2012; Hvidsten et al. 2014; Laaksonen et al. 2017). In addition, their abundance seems to be increasing, particularly in the more southern parts of this region (Jaenson et al. 2012; Sormunen et al. 2016b). Likewise, I. persulcatus has recently been found across Estonia and Finland, and in 2016 the species was reported for the first time from Sweden as well (Geller et al. 2012; Jaenson et al. 2016; Laaksonen et al. 2017).

In Finland, changes in the geographical range and abundance of ticks are also reflected in cases of tick-borne diseases: the annual numbers of microbiologically confirmed cases of Lyme borreliosis have been increasing since the mid 1990s (Sajanti et al. 2017). This has sparked public concern regarding the safety of outdoor activities, and consequently highlighted the need for developing novel control methods against the growing tick populations. Indeed, whereas several chemical pesticides and acaricides are already available, they have previously been shown to either have limited effectiveness in controlling ticks (regarding for example their lethality or duration of function) or to cause severe risk also to other, non-target organisms, limiting their wide-scale application (Stafford III 2004). Likewise, landscape management and reduction of tick host densities are effective methods for small-scale control, but not suited for covering large areas (Stafford III 2004). As such, control methods with wide applicability and little impact on the environment (apart from the target organism) are still sought after. Biological control is seen as one pathway towards this goal, with various species of nematodes, entomopathogenic fungi and parasitoids being assessed for control potential regarding ticks (Goolsby et al. 2015; Hartelt et al. 2008; Perinotto et al. 2012; Santos et al. 2017; Singh et al. 2018). However, only a few of these studies have focused on I. ricinus.

Biological control is the control of a pest by (the introduction of) a natural enemy. In this regard, the most effective and serviceable candidates are usually specialist species focusing on specific species/genera/families. The Encyrtidae is a species-rich family of small-sized parasitoid/hyperparasitoid wasps. It has been widely used in biological control of several important pest species. Ixodiphagus hookeri is an encyrtid wasp that specializes in parasitizing a wide range of hard tick species across the globe (Hu et al. 1998; Knipling and Steelman 2000; Takasu and Nakamura 2008; Plantard et al. 2012; Ramos et al. 2015). In Europe, they parasitize both larvae and nymphs of $I$. ricinus, with nymphs appearing to be the preferred targets (Takasu and Nakamura 2008; Collatz et al. 2011; Tijsse-Klasen et al. 2011; Plantard et al. 2012; Ramos et al. 2015). Following oviposition, wasp eggs hatch into larvae that begin feeding on the tick only after it has finished its blood meal in the nymph stage, leading to the death of the tick prior to its development to an adult (Hu and Hyland 1998). Due to their specificity and lethality, Ixodiphagus have long been a target of interest regarding the biological control of ticks (Larrousse et al. 1928; Mwangi et al. 1994; Knipling and Steelman 2000). However, few studies have been conducted regarding the biology, distribution, phenology, and/or parasitization rates of I. hookeri in Europe (Collatz et al. 2011; Tijsse-Klasen et al. 2011; Plantard et al. 2012; Ramos et al. 2015). 
From Fennoscandia, no such studies have been published. Therefore, in order to assess the potential of the species for tick control here at the northernmost limits of I. ricinus and $I$. persulcatus distribution, more data regarding their occurrence and biology are needed.

In southwestern Finland, the abundance of I. ricinus has dramatically increased in the twenty first century (Mäkinen et al. 2003; Sormunen et al. 2016a, b; Sormunen 2018). Although Ixodiphagus had never been reported from southwestern Finland prior to this study, it seemed logical that the presence of increasing numbers of suitable hosts should benefit any local Ixodiphagus populations, or even help in the establishment of novel populations in the area. Consequently, we set out to find Ixodiphagus specimens from Malaise trap samples collected in 2010-2016 from Seili, a rural island located in the Archipelago Sea in southwestern Finland, where studies had shown a dramatic increase in tick abundance over the past few decades (Sormunen et al. 2016a, b; Sormunen 2018) (Fig. 1). During these screenings, a single adult wasp was found from a sample collected in 2013.

In the current study, we describe the initial finding of I. hookeri from Seili Island, forming the second overall record of the species from Finland. Furthermore, we use various field survey and laboratory methods to assess the occurrence and abundance of the wasp, and whether parasitization of I. ricinus nymphs or adults occurs on the island.

\section{Materials and methods}

\section{Detection of Ixodiphagus hookeri from Seili Island}

The initial detection of $I$. hookeri on the island was made in 2016 from a Malaise trap sample collected from a grove of common hazel (Corylus avellana) on Seili Island in 2013 (Fig. 1). A single adult wasp was found and morphologically identified as a female $I$. hookeri based on the guidelines provided by Quaraishi (1958) (Fig. 2). These Malaise samples originated from an annually held terrestrial arthropod field course organized by the University of Turku Department of Biology and Biodiversity Unit. Malaise traps are annually set up for 1-3 weeks in July-August during the course. This particular trap had been active from July 22 to August 1, 2013. Several other Malaise samples collected during field courses in 2010-2016 were also screened, but no further I. hookeri were detected.

\section{Field surveys}

Following the discovery of the species on the island, field surveys were planned and carried out to procure further specimens from Seili during May-October 2017. Two Malaise traps (Marris House Net model) were set up, one at the locality of the initial wasp detection, the grove of common hazel (local I. ricinus density 13.2-88.9 nymphs $/ 100 \mathrm{~m}^{2}$ in 2012-2017), and the other in a patch of coniferous forest (I. ricinus density 8.6-30.4 nymphs/100 $\mathrm{m}^{2}$ ) (Fig. 1). Malaise trapping was carried out from May to October, encompassing roughly the whole activity period of I. ricinus in Finland. The traps were emptied every other week during this period.

In addition, sweep netting was performed in the immediate vicinity of 15 fixed 50-m tick study transects on the island (Sormunen et al. 2016a) (Fig. 1). All these transects have been found to harbor ticks in previous samplings, with annual nymph densities ranging from 0.4 to 88.9 nymphs $/ 100 \mathrm{~m}^{2}$ (assessment of tick densities described in Sormunen et al. 2016a). These transects are also the source of the samples used for laboratory analyses of 


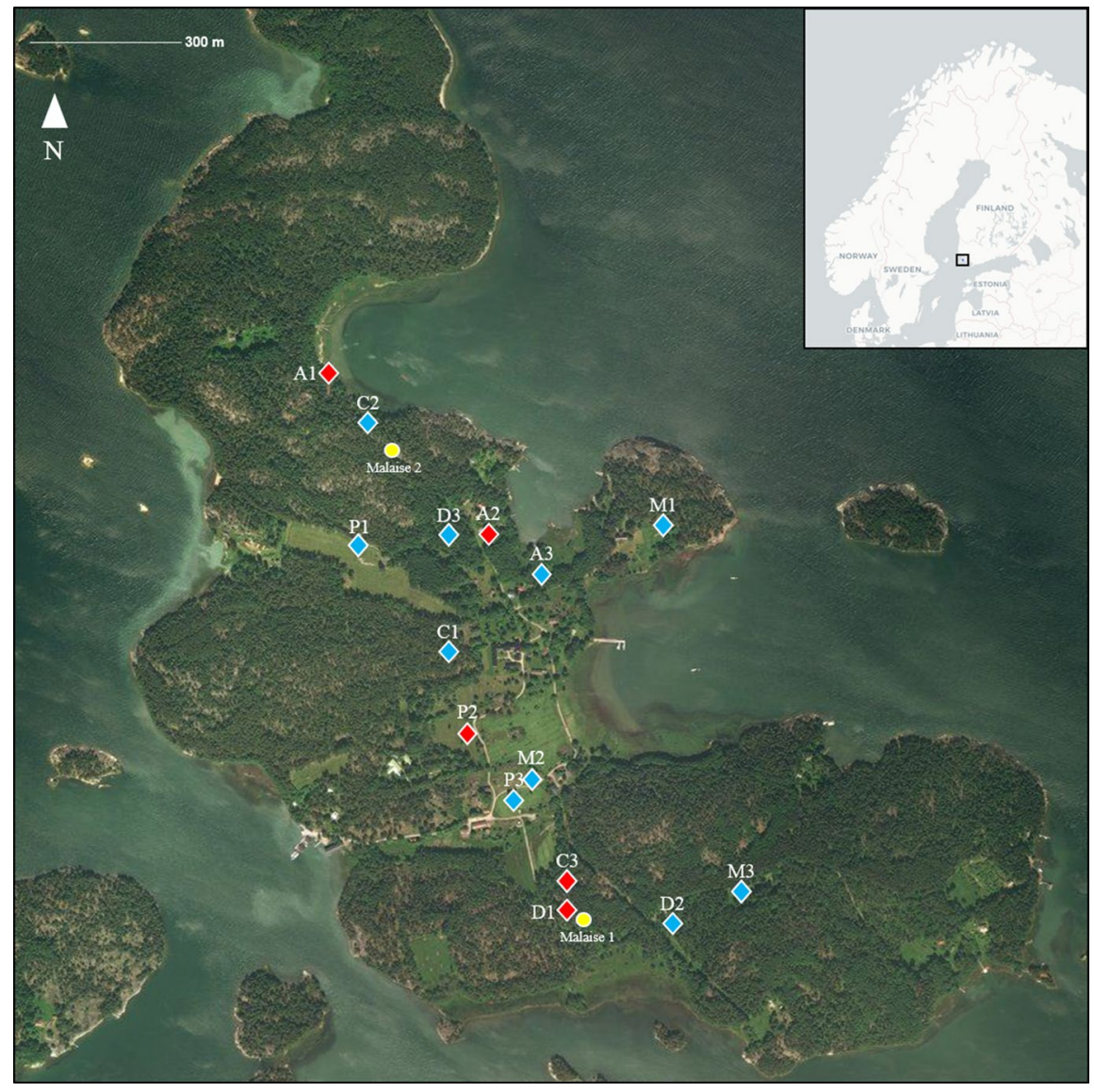

Fig. 1 Locations of the study transects and Malaise traps on Seili Island. The samples for tick parasitization analyses were collected from these transects between 2012 and 2014. Furthermore, sweep netting for adult wasps in 2017 was conducted within 1-2 m of the transects. Malaise 1 marks the location of the hazel grove Malaise trap, active in 2010-2016 and 2017; Malaise 2 marks the coniferous forest Malaise trap, active only in 2017. Transects that yielded samples positive for Ixodiphagus hookeri parasitization are marked in red $(\mathrm{D} 1=8$ positive samples, $\mathrm{C} 3=3, \mathrm{P} 2=1, \mathrm{~A} 2=1, \mathrm{~A} 1=1)$. Transect abbreviations: $A$ Alder thicker, $D$ deciduous forest, $C$ coniferous forest, $M$ meadow, $P$ pasture. Detailed descriptions of the biotopes associated with each transect can be found in the Supplementary Material

tick parasitization rates (see below). Sweep netting was conducted adjacent to (=within 1-2 $\mathrm{m}$ of) each transect between 10 am and 4 pm, once every 3 weeks, covering the whole length of the tick study transect. Small wasps were collected from the insect net with a suction sampler. Sweep netting was chosen for active sampling due to it being one of the most commonly used methods for collecting chalcidoid wasps (Noyes 1982).

All collected field samples were screened for I. hookeri during May-December 2017 at the Turku University Zoological Museum (ZMUT) using stereo microscopes (Olympus SZX10 and SZX16). Layer photos were taken in ZMUT using an Olympus SZX16 stereo microscope attached to a Canon EOS 7D mark II camera. The reference sample is deposited to ZMUT. 


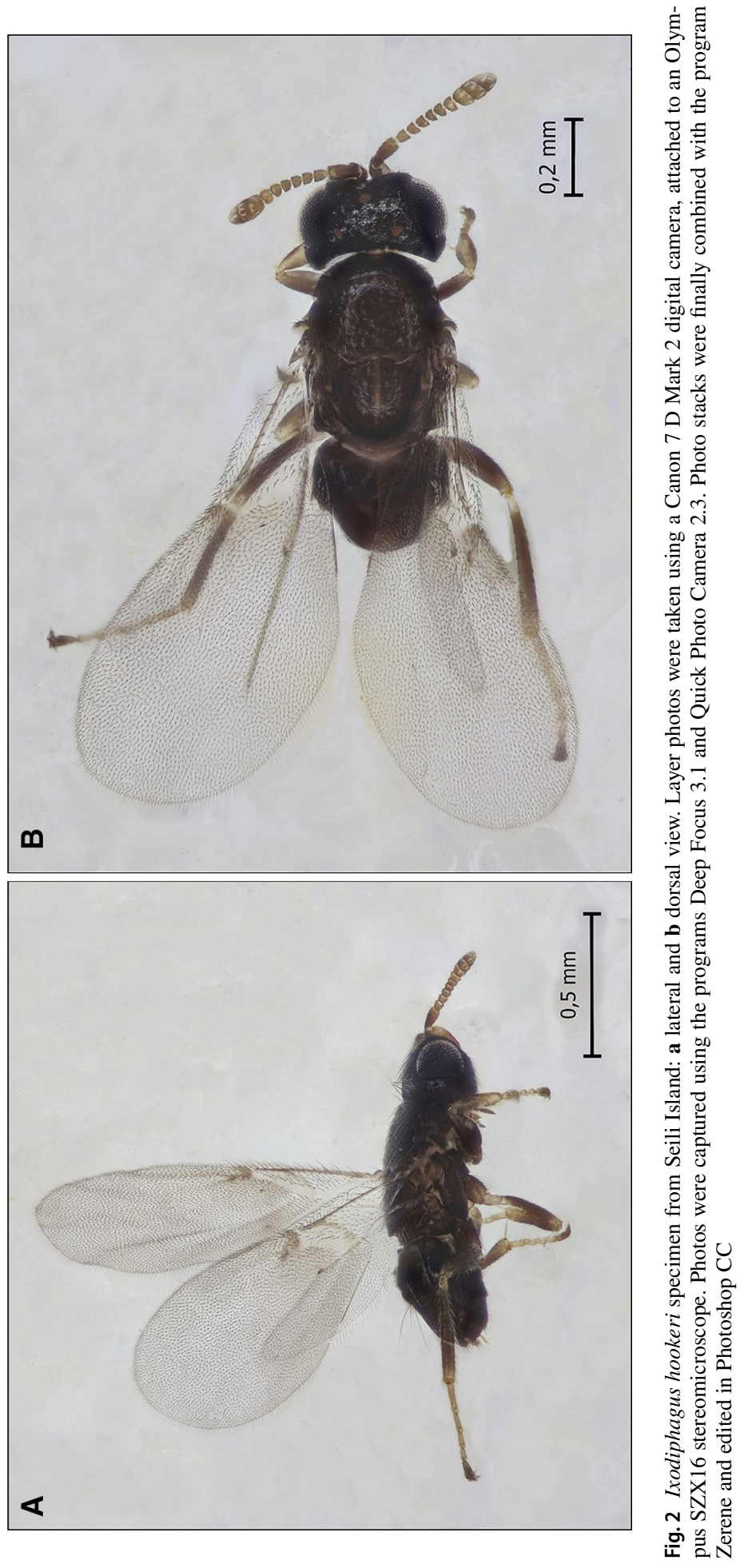




\section{Laboratory analysis}

A total of 974 DNA samples of I. ricinus collected by cloth dragging from the fixed study transects on Seili Island in 2012-2014 were screened for I. hookeri DNA (Sormunen et al. 2016a, b). The analyzed samples contained 472 nymphs in pools (136 samples; 2-14 individuals per sample), 748 individually extracted nymphs, and 90 individually extracted adults. Due to some of the analyzed nymphs being pooled samples, nymph parasitization rates were estimated as minimum infection rates (MIR).

Initial screening was carried out using real-time quantitative PCR (henceforth abbreviated qPCR), using SensiFAST ${ }^{\text {тм }}$ Probe Lo-ROX Kit (Bioline, Germany). All DNA samples were analyzed in three replicate reactions carried out on 384-well plates. At least three blank water samples were used as negative controls in each assay. Samples were considered positive only when successful amplification was detected in all three replicate reactions.

For qPCR, primers Iphag583f 5'-TTGCTGTTCCAACAGGAGTAAA-3' and Iphag820r 5'-CAAAAAATTGCAAAAACTGC-3', and dual-labeled probe Iphag612 s FAM-AGATGATAAGCTTCAATAAATGGAA-BHQ1, targeting Ixodiphagus COI, were used. These primers and probe had previously been successfully used to detect I. hookeri DNA from host seeking I. ricinus (Bohacsova et al. 2016). Assays were carried out in $8 \mu \mathrm{l}$ reaction volume, including $4 \mu \mathrm{l}$ SensiFAST Probe Lo-ROX Kit, $400 \mathrm{nM}$ forward primer, $400 \mathrm{nM}$ reverse primer, $200 \mathrm{nM}$ probe, $0.2 \mu 1 \mathrm{ddH}_{2} \mathrm{O}$, and $3 \mu \mathrm{l}$ DNA sample. Thermal cycling profile was $95{ }^{\circ} \mathrm{C}$ for $5 \mathrm{~min}$, followed by 50 cycles of $95{ }^{\circ} \mathrm{C}$ for $10 \mathrm{~s}$ and $60{ }^{\circ} \mathrm{C}$ for $30 \mathrm{~s}$.

Samples found positive by qPCR were amplified, and subsequently Sangersequenced, using conventional PCR primers Ihookcox1F 5'-TTAGATGATTAGCTT CAATAAATGGAAT-3' and Ihookcox1R 5'-CCAAAAATTGCAAAAACTGCTCCT AT-3' targeting Ixodiphagus COI (Ramos et al. 2015). PCR was carried out in $15 \mu \mathrm{l}$

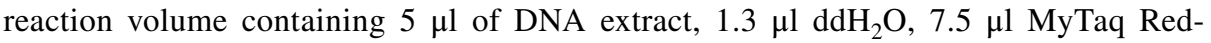
Mix polymerase mix (product number BIO-25048, Bioline, England), $400 \mathrm{nM}$ forward primer, and $400 \mathrm{nM}$ reverse primer. Water samples were used as blank controls in each PCR batch. Thermal cycling was performed with the following program: $95{ }^{\circ} \mathrm{C}$ for $3 \mathrm{~min}$, then 40 cycles of $95{ }^{\circ} \mathrm{C}$ for $15 \mathrm{~s}, 54^{\circ} \mathrm{C}$ for $30 \mathrm{~s}$, and $72{ }^{\circ} \mathrm{C}$ for $1 \mathrm{~min}$. Successful PCR products were purified by mixing $1 \mu \mathrm{l}$ EXO I enzyme, $1 \mu \mathrm{rSAP}$ enzyme, and $8 \mu \mathrm{l}$ of PCR product, after which the samples were first incubated 5 min at $37{ }^{\circ} \mathrm{C}$ and then heated $10 \mathrm{~min}$ at $80^{\circ} \mathrm{C}$. Purified samples were sent to Macrogen Europe (The Netherlands) for sequencing.

\section{Results}

A total of 75 sweep netting samples (3.75 km of sweep netting) and 24 Malaise samples (21 weeks of trapping) collected during May-October 2017 were screened for the presence of I. hookeri. Neither of the field survey methods produced further specimens.

Laboratory screening revealed I. hookeri DNA in 14 nymph samples, with annual minimum infection rates (MIR) of 2.3, 0.4, and $0.5 \%$ in 2012, 2013, and 2014, respectively. All adult samples were negative. A majority (11/14) of positive samples came from within, or close proximity of $(<100 \mathrm{~m})$, the grove of common hazel from 
which the adult I. hookeri specimen was obtained in 2013 (Fig. 1). The rate of I. ricinus nymphs infected by I. hookeri was higher in the vicinity of the hazel grove than expected by random co-occurrence (5.6 expected, 11 observed; Chi Square, $p=0.012$, $\mathrm{n}=819$ ), and lower than expected in other areas (7.4 expected, 3 observed; Chi Square, $\mathrm{p}=0.012, \mathrm{n}=819)$.

Out of the 14 positive samples, 11 were successfully sequenced and confirmed as $I$. hookeri. The sequences displayed a $100 \%$ match to an I. hookeri sample obtained from a wasp that had emerged from a parasitized I. ricinus in France (GenBank accession: JQ315225.1) (Plantard et al. 2012). For the remaining three samples, poor quality of the sequence data prevented identification. A representative sequence has been deposited on GenBank under accession number MN243784.

\section{Discussion}

The discovery of the chalcidoid tick parasitoid I. hookeri on the island of Seili forms the second published record of the species from Finland, with the only previous detection being from Lohja in southern Finland in 1950 (Koponen and Vikberg 2015). The Seili specimen was found from a Malaise trap sample collected from a hazel grove between July 22 and August 1, 2013. The discovery of the wasp in late summer is in line with observations from Germany, where adult wasps were reportedly only found during 3-5 weeks in late summer/early autumn (Collatz et al. 2011). It was suggested by Collatz et al. (2011) that wasp occurrence in late summer is probably a consequence of synchronization with tick feeding activity. In 2013, nymph activity in the tick study transect adjacent to the Malaise trap that produced the wasp sample (D1 in Fig. 1) peaked in July, and the overall peak of nymph activity on the island was observed in August-September. These observations concur with the notion of late season parasite-host activity synchronization (Collatz et al. 2011).

Overall, highly varying rates of $I$. hookeri parasitization in host-seeking $I$. ricinus nymphs have been reported from Europe (22\% in France, $7.2 \%$ in Italy, $2-4 \%$ in Germany, 9.6\% in the Netherlands) (Collatz et al. 2011; Tijsse-Klasen et al. 2011; Plantard et al. 2012; Ramos et al. 2015). Whereas the rates of parasitization observed here were low (even considering minimum infection rates usually provide underestimates), higher rates in, for example, France and the Netherlands suggest that Ixodiphagus may have tangible impact on tick populations. In regard to the low parasitization rates observed in the current study, major increases in tick abundance in the study area appear to have occurred relatively recently (Sormunen et al. 2016b; Sormunen 2018). Consequently, it is possible that the wasp population has not had sufficient time to respond to higher tick numbers, as a time lag may exist between increases in host/prey and specialist enemy populations (Snyder and Ives 2003).

Ixodiphagus spp. are most often detected from tick nymphs, but parasitization also occurs in the larval stage (Hu et al. 1998; Knipling and Steelman 2000; Collatz et al. 2011). Additionally, studies concerning host finding by I. hookeri have suggested that odors from tick host animals are the main attractants for the wasps, and that the majority of parasitization of ticks consequently occurs on the hosts (Demas et al. 2000; Collatz et al. 2010). Therefore, as the development of deposited I. hookeri eggs commences only after the nymphal blood meal, parasitized host-seeking nymphs collected from vegetation likely consist mostly of individuals parasitized as either questing, feeding, or 
engorged larvae (Collatz et al. 2011). As such, the overall parasitization rate of I. ricinus nymphs, and therefore also the impact of parasitization on the whole tick population, may be much higher than displayed in analysis of only host-seeking nymphs. Consequently, screening of tick larvae (both questing and engorged) and engorged nymphs should also be conducted for a more thorough assessment of parasitism.

Whatever the actual rate of parasitization on the island, local tick abundance has been increasing since 2012 (Sormunen 2018). However, in contrast, parasitization rates of host-seeking nymphs decreased in 2013-2014 compared to 2012. Although the exact reasons for this remain undetermined, these observations could potentially be due to nymphs, as the preferred targets of parasitization, being more numerous in nature in later years. More nymphs being parasitized could reduce the number of larvae (as secondary targets) being parasitized (Takasu and Nakamura 2008; Collatz et al. 2011). As nymph parasitization is thought to happen to a large degree on tick host animals (Demas et al. 2000; Collatz et al. 2010), increases in their parasitization might not be detected by screening host-seeking individuals.

Based on the molecular evidence in this study, the parasitization of nymphs on the island seems to be focused around the grove of common hazel, with 11/14 infected nymph samples being from the vicinity. Interestingly, the prior discovery of an adult $I$. hookeri from Finland was also from a hazel grove, suggesting particular suitability of the habitat for I. ricinus and/or I. hookeri population upkeep. Indeed, at least the hazel grove in Seili forms a very distinct biotope compared with the rest of the island. As the canopy height of common hazel is lower than that of other typical trees on the island and the extent of canopy coverage also higher, the grove may offer small mammals, the preferred hosts of juvenile I. ricinus, increased protection from avian predators. Furthermore, they provide hazelnuts as food for rodents. Both these factors may contribute to increased rodent density in the area. Unfortunately, the exact host animal composition and density in the grove has not been determined, so its deviance from other habitats in this regard cannot be ascertained. The extensive canopy coverage and high amounts of leaf litter in the grove also offer suitable shelters and a shady-and consequently cooler and more humid-environment for ticks and wasps, increasing their survival and chances for questing. However, whether parasitization happens more commonly in the hazel grove due to higher local tick or wasp abundance because of these aforementioned phenomena, or some completely different factor making the area more suitable for the wasp, remains to be determined. Further surveys on the study site Seili will be aimed at late season field sampling of $I$. hookeri and the observing of parasitization patterns by molecular analysis of tick samples from more recent years. Hopefully more data will help determine whether the island indeed has an established I. hookeri population, or whether the parasitization observed on the island is due to sporadic invasions, for example due to parasitized ticks being transported to the island by migrating birds during their long (3-8 days) blood meals. Overall, knowledge of the distribution and abundance of I. hookeri in Finland is needed to assess whether the Finnish wasp population is decreasing or increasing, and, consequently, whether the maximum impact they can naturally have on the rapidly increasing Finnish tick populations has been reached.

Acknowledgements Open access funding provided by University of Turku (UTU) including Turku University Central Hospital. We would like to thank the Jane and Aatos Erkko Foundation, the University of Turku Graduate School and Carl Tryggers Stiftelse för Vetenskaplig Forskning for funding the project. Likewise, thank you to Niko Tanski and Päivi Kotitalo, who were in charge of the maintenance and emptying of the Malaise traps on Seili Island, Henrik Rousi for his help with screening the Malaise trapping material, and Dr. John Noyes (The Natural History Museum, UK) for his help with the morphological identification of our Ixodiphagus. 
Funding This study was funded by the Jane and Aatos Erkko Foundation, the University of Turku Graduate School (salary for JJS) and Carl Tryggers Stiftelse för Vetenskaplig Forskning (funding for EJV).

\section{Compliance with ethical standards}

Conflict of interest On behalf of all authors, the corresponding author states that there is no conflict of interest.

Open Access This article is distributed under the terms of the Creative Commons Attribution 4.0 International License (http://creativecommons.org/licenses/by/4.0/), which permits unrestricted use, distribution, and reproduction in any medium, provided you give appropriate credit to the original author(s) and the source, provide a link to the Creative Commons license, and indicate if changes were made.

\section{References}

Bohacsova M, Mediannikov O, Kazimirova M, Raoult D, Sekeyova Z (2016) Arsenophonus nasoniae and rickettsiae infection of Ixodes ricinus due to parasitic wasp Ixodiphagus hookeri. PLoS ONE 11(2):e0149950. https://doi.org/10.1371/journal.pone.0149950

Collatz J, Fuhrmann A, Selzer P, Oehme RM, Hartelt K, Kimmig P et al (2010) Being a parasitoid of parasites: host finding in the tick wasp Ixodiphagus hookeri by odours from mammals. Entomol Exp Appl 134(2):131-137. https://doi.org/10.1111/j.1570-7458.2009.00943.x

Collatz J, Selzer P, Fuhrmann A, Oehme RM, Mackenstedt U, Kahl O et al (2011) A hidden beneficial: biology of the tick-wasp Ixodiphagus hookeri in Germany. J Appl Entomol 135(5):351-358. https://doi.org /10.1111/j.1439-0418.2010.01560.x

Demas FA, Hassanali A, Mwangi EN, Kunjeku EC, Mabveni AR (2000) Cattle and Amblyomma variegatum odors used in host habitat and host finding by the tick parasitoid, Ixodiphagus hookeri. J Chem Ecol 26(4):1079-1093. https://doi.org/10.1023/A:1005497201074

Geller J, Nazarova L, Katargina O, Järvekülg L, Fomenko N, Golovljova I (2012) Detection and genetic characterization of relapsing fever spirochete Borrelia miyamotoi in Estonian ticks. PLoS ONE 7(12):e51914

Goolsby JA, Mays DT, Schuster GL, Kashefi J, Smith L, Amalin D et al (2015) Rationale for classical biological control of cattle fever ticks and proposed methods for field collection of natural enemies. Subtrop Agric Environ 66:7-15

Hartelt K, Wurst E, Collatz J, Zimmermann G, Kleespies RG, Oehme RM et al (2008) Biological control of the tick Ixodes ricinus with entomopathogenic fungi and nematodes: preliminary results from laboratory experiments. Int J Med Microbiol 298(1):314-320

Hu R, Hyland KE (1998) Effects of the feeding process of Ixodes scapularis (Acari: Ixodidae) on embryotic development of its parasitoid, Ixodiphagus hookeri (Hymenoptera: Encyrtidae). J Med Entomol 35:1050-1053

Hu R, Hyland KE, Oliver JH (1998) A review on the use of Ixodiphagus wasps (Hymenoptera: Encyrtidae) as natural enemies for the control of ticks (Acari: Ixodidae). Syst Appl Acarol 3(1):19-28. https://doi. org/10.11158/saa.3.1.3

Hvidsten D, Stuen S, Jenkins A, Dienus O, Olsen RS, Kristiansen B-E et al (2014) Ixodes ricinus and Borrelia prevalence at the Arctic Circle in Norway. Ticks Tick-Borne Dis 5(2):107-112

Jaenson TGT, Jaenson DGE, Eisen L, Petersson E, Lindgren E (2012) Changes in the geographical distribution and abundance of the tick Ixodes ricinus during the past 30 years in Sweden. Parasites Vectors $5(1): 1-15$

Jaenson TGT, Värv K, Fröjdman I, Jääskeläinen A, Rundgren K, Versteirt V et al (2016) First evidence of established populations of the taiga tick Ixodes persulcatus (Acari: Ixodidae) in Sweden. Parasites Vectors 9(1):377. https://doi.org/10.1186/s13071-016-1658-3

Jore S, Viljugrein H, Hofshagen M, Brun-Hansen H, Kristoffersen AB, Nygård K et al (2011) Multi-source analysis reveals latitudinal and altitudinal shifts in range of Ixodes ricinus at its northern distribution limit. Parasites Vectors 4(1):84

Knipling EF, Steelman CD (2000) Feasibility of controlling Ixodes scapularis ticks (Acari: Ixodidae), the vector of lyme disease, by parasitoid augmentation. J Med Entomol 37(5):645-652. https://doi. org/10.1603/0022-2585-37.5.645 
Koponen M, Vikberg V (2015) Suomen hyppykiilupistiäiset [Check list of the species of Encyrtidae in Finland] (Hymenoptera, Chalcidoidea, Encyrtidae). Sahlbergia, pp 12-43

Laaksonen M, Sajanti E, Sormunen JJ, Penttinen R, Hänninen J, Ruohomäki K et al (2017) Crowdsourcingbased nationwide tick collection reveals the distribution of Ixodes ricinus and I. persulcatus and associated pathogens in Finland. Emerg Microbes Infect 6:e31. https://doi.org/10.1038/emi.2017.17

Larrousse F, King AG, Wolbach SB (1928) The overwintering in Massachusetts of Ixodiphagus caucurtei. Science 67(1735):351-353

Mäkinen J, Vuorinen I, Oksi J, Peltomaa M, He Q, Marjamäki M et al (2003) Prevalence of granulocytic Ehrlichia and Borrelia burgdorferi sensu lato in Ixodes ricinus ticks collected from Southwestern Finland and from Vormsi Island in Estonia. Apmis 111(2):355-362

Mwangi EN, Kaaya GP, Essuman S, Kimondo MG (1994) Parasitism of Amblyomma variegatum by a hymenopteran parasitoid in the laboratory, and some aspects of its basic biology. Biol Control 4(2):101-104

Noyes JS (1982) Collecting and preserving chalcid wasps (Hymenoptera: Chalcidoidea). J Nat Hist $16(3): 315-334$

Perinotto WMS, Terra ALM, Angelo IC, Fernandes ÉKK, Golo PS, Camargo MG et al (2012) Nomuraea rileyi as biological control agents of Rhipicephalus microplus tick. Parasitol Res 111:1743-1748

Plantard O, Bouju-Albert A, Malard M-A, Hermouet A, Capron G, Verheyden H (2012) Detection of Wolbachia in the tick Ixodes ricinus is due to the presence of the hymenoptera endoparasitoid Ixodiphagus hookeri. PLoS ONE 7(1):e30692. https://doi.org/10.1371/journal.pone.0030692

Quaraishi MS (1958) Morphology of two chalcidoid parasites of ticks, Hunterellus hookeri Howard, 1908, and Ixodiphagus texanus Howard, 1907. Am Midl Nat 59(2):489-504. https://doi.org/10.2307/24224 94

Ramos RAN, Campbell BE, Whittle A, Lia RP, Montarsi F, Parisi A et al (2015) Occurrence of Ixodiphagus hookeri (Hymenoptera: Encyrtidae) in Ixodes ricinus (Acari: Ixodidae) in Southern Italy. Ticks Tickborne Dis 6(3):234-236. https://doi.org/10.1016/j.ttbdis.2015.01.001

Sajanti E, Virtanen M, Helve O, Kuusi M, Lyytikäinen O, Hytönen J et al (2017) Lyme Borreliosis in Finland, 1995-2014. Emerg Infect Dis 23(8):1282-1288. https://doi.org/10.3201/eid2308.161273

Santos MAB, de Macedo LO, de Souza IB, do Nascimento Ramos CA, Alves LC, Ramos RAN et al (2017) Larvae of Ixodiphagus wasps (Hymenoptera: Encyrtidae) in Rhipicephalus sanguineus sensu lato ticks (Acari: Ixodidae) from Brazil. Ticks Tick-Borne Dis 8(4):564-566

Singh NK, Goolsby JA, Shapiro-Ilan DI, Miller RJ, Setamou M, Perez de Leon AA (2018) Effect of immersion time on efficacy of entomopathogenic nematodes against engorged females of cattle fever tick, Rhipicephalus (= Boophilus) microplus. Southwest Entomol 43(1):19-29

Snyder WE, Ives AR (2003) Interactions between specialist and generalist natural enemies: parasitoids, predators, and pea aphid biocontrol. Ecology 84(1):91-107

Sormunen J (2018) Questing ticks, hidden causes: tracking changes in Ixodes ricinus populations and associated pathogens in southwestern Finland. Doctoral dissertation, University of Turku. http://urn.fi/ URN:ISBN:978-951-29-7492-4

Sormunen JJ, Klemola T, Vesterinen EJ, Vuorinen I, Hytönen J, Hänninen J et al (2016a) Assessing the abundance, seasonal questing activity, and Borrelia and tick-borne encephalitis virus (TBEV) prevalence of Ixodes ricinus ticks in a Lyme borreliosis endemic area in Southwest Finland. Ticks Tick Borne Dis 7(1):208-215. https://doi.org/10.1016/j.ttbdis.2015.10.011

Sormunen JJ, Penttinen R, Klemola T, Hänninen J, Vuorinen I, Laaksonen M et al (2016b) Tick-borne bacterial pathogens in southwestern Finland. Parasites Vectors 9(1):1-10. https://doi.org/10.1186/s1307 $1-016-1449-\mathrm{X}$

Stafford KC III (2004) Tick management handbook. An integrated guide for homeowners, pest control operators and public health officials for the prevention of tick-associated diseases. The Connecticut Agricultural Experiment Station, New Haven

Takasu K, Nakamura S (2008) Life history of the tick parasitoid Ixodiphagus hookeri (Hymenoptera: Encyrtidae) in Kenya. Biol Control 46(2):114-121

Tijsse-Klasen E, Braks M, Scholte E-J, Sprong H (2011) Parasites of vectors-Ixodiphagus hookeri and its Wolbachia symbionts in ticks in the Netherlands. Parasites Vectors 4(1):228. https://doi. org/10.1186/1756-3305-4-228

Publisher's Note Springer Nature remains neutral with regard to jurisdictional claims in published maps and institutional affiliations. 